\title{
Philosophical Idling and Philosophical Relativity
}

\author{
Robert K. Garcia \\ Texas A\&M University \\ robertkgarcia@gmail.com \\ www.robertkgarcia.com
}

\section{Request from the author:}

If you would be so kind, please send me a quick email if ...

- you are reading this for a university or college course, or

- you are citing this in your own work.

It is rewarding to know how my work is being used, especially if it has been adopted as required or recommended reading.

Thank you.

\section{Citation Information:}

Garcia, R. (2015). "Philosophical Idling and Philosophical Relativity," Ratio, 28(1), 51-64. 


\title{
PHILOSOPHICAL IDLING AND PHILOSOPHICAL RELATIVITY
}

\author{
Robert K. Garcia
}

\begin{abstract}
Peter Unger has challenged philosophical objectivism, the thesis that traditional philosophical problems have definite objective answers. He argues from semantic relativity for philosophical relativity, the thesis that for certain philosophical problems, there is no objective answer. I clarify, formulate and challenge Unger's argument. According to Unger, philosophical relativism explains philosophical idling, the fact that philosophical debates appear endless, philosophical disagreements seem irresolvable, and very little substantial progress seems made towards satisfactory and definite answers to philosophical problems. I argue, however, that the reality of philosophical idling is doubtful and, ironically, undermined by philosophical relativism. I then raise problems for several steps in Unger's argument for philosophical relativity. I conclude by arguing that philosophical relativism can avoid self-defeat only by an ad hoc limitation of its scope. ${ }^{1}$
\end{abstract}

Peter Unger has challenged the pervasive belief that traditional philosophical problems have definite objective answers. ${ }^{2}$ For the sake of simplicity, I will call the content of this belief philosophical objectivism, or PO. Unger tempers his challenge with a bit of modesty. He intends to cast doubt on PO, but not necessarily refute it. Indeed, he does not even expect his arguments to compel many to abandon PO. Nevertheless he argues that there is no objective answer for certain philosophical problems. The latter thesis is called philosophical relativity, or philosophical relativism (PR).

This paper will proceed in the following manner. I begin by discussing the alleged explanandum PR is supposed to explain, and noting how Unger weighs other rival explanations relative to

1 For comments and discussion I wish to thank E. J. Coffman, Nathan King, Alvin Plantinga, Mitch Stokes, and an anonymous referee of the journal.

2 Unger first presents this challenge in Philosophical Relativity (Minneapolis: University of Minnesota Press, 1984), which was reissued in 2002 by Oxford University Press. Unger also develops it in Part III of Philosophical Papers: Volume One (Oxford: Oxford University Press, 2002). 
PR. Then I present Unger's case for PR, concluding the exposition by offering an formulation of his argument. This formalization will facilitate my critique, which has three basic parts. First, I argue that the reality of PR's intended explanandum is both doubtful independent of PR and undermined by PR. Second, I criticize Unger's argument for PR at several steps. Third, I conclude by arguing that PR can avoid self-defeat only by an ad hoc limitation of its scope.

\section{Philosophical Idling and Unger's Case for PR}

In perennial philosophical disputes, such as disputes over the problem of determinism or the problem of knowledge, both sides are typically objectivists (i.e., persons assuming or affirming PO). Thus, for example, while philosophers disagree over whether determinism impinges upon human freedom, most will agree that there is a correct view on the matter, even if it remains unknown. Yet, Unger urges, despite the optimism of objectivists, their efforts to discover the objectively right answers seem to go nowhere. The debates appear endless, and very little substantial progress seems made towards satisfactory and definite answers. ${ }^{3}$ This apparent idling of philosophy needs to be explained; and this prompts Unger to ask his central 'higher-level' question: 'Why do these debates go on and on with so little in the way of results?'. ${ }^{4}$ The objectivists, of course, have several explanations ready, each of which is consistent with PO: our cognitive faculties are not up to the task, the problems are too difficult, we have yet to gather all the relevant data, etc. Unger, on the other hand, recommends PR as another possible explanation, one not compatible with PO. Since Unger sees PR as 'casting doubt' on PO, we may understand him as claiming that $\mathrm{PR}$ is more plausible than PO. ${ }^{5}$ And, although he does not use the term, it seems reasonable to infer from his recommendation of PR that Unger considers PR to be the best explanation of the apparent idling.

Unger argues for PR on the basis of what he calls the hypothesis of Semantic Relativity (SR): 'for a given group of speakers, there is no single semantics that is the unique, objectively real semantics

Philosophical Relativity, p. 4.

Ibid.

Philosophical Relativity, p. 3. 
of that group. ${ }^{9}$ Unger offers this hypothesis in light of what he takes to be two conflicting approaches to semantics. Before sketching these approaches, it is important to note Unger's general view on semantics.

According to Unger, semantic theories are types of explanations. In particular, a semantic theory (or approach) amounts to an explanation of two basic facts with respect to a group of speakers: the expressions (i.e., utterances or sounds) of group members, and the effects of these expressions on the thoughts, experiences, and behavior of the members. Thus, each way of explaining how a group member's expression produces its effects on the group will amount to a different semantics (or semantic approach) for that group.

Given this view of semantics, Unger arrives at SR in two steps. First, he argues that there are two conflicting semantic approaches. Second, he argues that there is no fact of the matter regarding which of these approaches is correct. I will present each step in turn.

The two semantic approaches are contextualism and invariantism, and each posits a different explanation of how certain linguistic expressions cause thought and behavior. ${ }^{7}$ In particular, each view posits a meaning for an utterance and a process by which that utterance causes a relevant thought (and thus behavior) in an audience. Contextualism posits a complex semantics and a simple process; invariantism posits a simple semantics and a complex process.

To illustrate these views, suppose a fellow named Felipe says to his friend Julia, 'The field is flat.' According to the contextualist, Felipe's statement actually means something quite complex, like: 'According to contextually relevant standards, a certain indicated field is sufficiently close to being such that nothing could ever be flatter than it is.' ${ }^{8}$ And, Julia hears it as such - her thought is now about that complex meaning and she behaves accordingly. The process, however, is simple: Julia's thought is about a complex proposition because the meaning of Felipe's utterance was that complex proposition.

6 Philosophical Relativity, p. 6.

7 Unger ties behavior and thought together in that a thought is correctly attributed to a person only in so far as that thought can 'serve to explain, however directly or obliquely, purposive behavior, actual and potential' (Philosophical Relativity, pp. 7-8).

Philosophical Relativity, pp. 6-7. 
For the invariantist, things are the other way around. The meaning of Felipe's utterance is a simple proposition, like: 'That field is absolutely flat.' However, there is a complex process between Julia's grasp of this simple meaning and the relevant thought she is led to focus upon. This process amounts to Julia noticing that this proposition is both false and irrelevant, and in light of the context, inferring from this falsehood a relevant and true proposition (and behaving accordingly). The latter proposition is the same complex proposition the contextualist posited as the meaning of Felipe's actual utterance. These are the two conflicting semantic approaches.

It is important to note that the two views will not necessarily posit different explanations for every expression. The contextualist will agree that some expressions should be explained on invariantist terms; for other expressions, the invariantist returns the favor. Nevertheless, there is a particular range of expressions over which the two views disagree. Call expressions in this range 'vague expressions.'

Having delineated these two semantic theories, Unger makes his final step to SR. He now claims that there is no fact of the matter as to whether contextualism or invariantism provides the correct interpretation of vague expressions. It seems that Unger bases this claim upon the (alleged) fact that we cannot determine whether contextualism or invariantism provides the correct interpretation of vague expressions. He presents several vague expressions, for which each theory has a different and conflicting interpretation. He then argues that since either theory's explanation is sufficient, we have no way to determine which is correct (though by habit we tend to prefer contextualism). Thus, Unger concludes that there is no correct interpretation of the vague expression.

This is Unger's case for SR, and from here it is a short step to PR. The move from SR to PR is simple. Unger argues that certain philosophical problems, as typically stated, are vague expressions. Thus, these problems have no definite meaning and thus no definite answer. An important example, he urges, is the problem of knowledge. If we take an invariantist interpretation of this problem, the sceptic wins. If we take a contextualist reading, the non-sceptic wins. But, there is no fact of the matter as to which interpretation is correct, so there is no fact of the matter as to who wins. No wonder the problem of knowledge is perennial, and its attendant debate endless - we may as well have been searching for 
the sceptic who doubts all and only those who do not doubt themselves!

Although Unger does not offer a syllogistic formulation of his argument for PR, I will offer one to elucidate his key moves and assumptions, and facilitate my critique. In its most basic form, Unger's argument appears to run as follows:

(1) Invariantism and contextualism give rival semantic theories for vague expressions.

(2) A semantic theory is an explanation of the behavioral effects of an expression.

(3) Thus, invariantism and contextualism give rival explanations of the behavioral effects of vague expressions.

(4) Invariantism and contextualism provide equally sufficient explanations of the behavioral effects of vague expressions.

(5) Thus, there is no fact of the matter as to whether invariantism or contextualism gives the correct explanation of the behavioral effects of vague expressions.

(6) Thus, there is no fact of the matter as to the correct explanation of the behavioral effects of vague expressions.

(7) Thus, Semantic Relativity is true: there is no fact of the matter as to the correct interpretation of vague expressions.

(8) Expressions of certain philosophical problems are vague expressions.

(9) Thus, there is no fact of the matter as to the correct interpretation of certain philosophical problems.

(10) Thus, Philosophical Relativity is true: certain philosophical problems lack a definite solution.

An immediate worry concerns whether or not this formulation is charitable and accurate. After all, and as we will see, the above argument is invalid without additional premises. Nevertheless, it seems that the above formulation does reflect how Unger presents his case for PR; and I will argue that worries about validity pertain to his case and not merely my rendition of it. I will further contend that these worries are substantial, and that Unger's case for PR falters on them.

The order of my comments on Unger's argument will differ from the order of the above premises. I will begin by calling into question the proffered motive for PR (i.e., the idling claim). Then 
I will consider the above formulation, noting and challenging a suppressed premise between (5) and (6). Next, I will clarify (4) and the nature of the inference from (4) to (5). Then I will consider the status of (2) together with the inference from (9) to (10). Finally, I will consider whether PR or Unger's argument for PR is self-defeating.

\section{Challenges for Unger's Case}

Before raising some challenges for Unger's argument for PR, I would like to offer a comment on the proffered motive for PR. According to Unger, we need an explanation as to why philosophy seems to idle, and Unger opts for PR. And indeed, PR does provide an explanation. After all, if there were no answers to certain philosophical questions then, necessarily, no genuine philosophical progress could be had with respect to answering those questions (although we still might think we had made progress). On a charitable reading, Unger does not claim that the relevant explanandum is the actual idling of philosophy but only the apparent idling of philosophy. And here too PR seems to have some explanatory power: although PR would not entail the apparent idling, it would certainly be a plausible explanation of it.

However, it is not obvious that philosophy does idle, or even that philosophy appears to idle. In particular, one could argue that philosophical progress has been made on the problems of freedom and knowledge - the two problems Unger mentions to illustrate the apparent idling. What this shows is that if one does not affirm the idling claim - if one either denies or withholds on it - then one does not have an explanandum for PR to explain. Furthermore, if one denies the idling claim and, instead, thinks that there is evidence we have made real progress, then one lacks the relevant explanandum and has a reason to not affirm PR. To be sure, however, Unger's case for PR is based on SR and thus is independent of the idling claim. Nevertheless, one might argue that we have very good reason to think that philosophical progress has been made, and that any thesis (such as SR) entailing that progress is illusory is thus unwarranted or even false. Thus, it seems that although PR may be true, the reality of its intended explanandum is at least contentious, and is arguably illusory.

Finally, I would like to raise a complaint about the idling claim that will betoken a recurring type of problem for Unger. The 
recurring worry concerns whether or not certain premises in the case for PR are permissible if PR is itself true. That is, the worry is whether Unger's case for PR is in some way self-defeating. Now, strictly speaking, the idling claim is a motive for PR, not a premise in the case for PR. Nevertheless, PR may undermine the idling claim. Note that the claim answers something like the following question: 'Have we made any definite and satisfying progress towards answering perennial philosophical questions?' The idling claim provides the following answer: 'Apparently not.' However, if PR is true, the above question might not have an answer, depending on whether or not the question is a vague expression. Prima facie, terms like 'satisfying,' 'definite,' and especially 'progress' seem no less vague than 'know' or 'free' (Unger's paradigmatic vague-expression-making terms). Thus, it seems that the idling claim tries to answer a question that PR says has no answer. At any rate, I will note and accumulate several instances of this worry along the way, and will conclude the paper by considering the possibility of self-defeat.

Note that (6) follows from (5) only if it is impossible that there be some other semantic theory which can provide the correct interpretation of a vague expression even if neither contextualism nor invariantism can do so. We can now state and number this premise:

(5.1) The behavioral effects of a vague expression have a correct explanation only if either contextualism or invariantism (but not both) provides it.

Although unstated, this assumption is obviously necessary for Unger's argument. Otherwise, there is no reason to infer (6) from (5). But is (5.1) correct? I, for one, would like to see an argument for it. However, suppose that Unger either assumes (5.1) or has an argument ready for it. In either case (5.1) looks like a significant philosophical discovery, one answering to a philosophical question like 'How many distinct semantic theories are possible, and what accounts do they give?' Indeed, one might count this discovery as philosophical progress. More importantly, (5.1) seems admissible in support of PR only if the question to which it answers is not the kind of question (i.e., a vague one) denied a definite answer by PR. I will return to this problem below.

I will now consider (4) and how it might entail (5). Two questions will concern us: First, how must (4) be construed so as to 
entail (5)? Second, what of that construal? One way to read (4) is to read it as making a weak epistemic claim, to the effect that given the facts at our disposal, contextualism and invariantism provide equally sufficient explanations. This rendering would not entail (5), however, since it is possible that we have yet to consider some of the relevant facts (perhaps because they are beyond our cognitive ken).

The problem with inferring (5) from (4) has to do with the nature of explanations. Normally, explanations are psychologically satisfying accounts of phenomena, which appeal to whatever explanatory virtues and resources are relevant and available. Thus, explanations typically do not have ontological entailments. Even the best explanation of a phenomenon will at best be only highly probable. Nevertheless, there is a way to construe (4) as a claim about explanation, which nevertheless has ontological entailments. In order to entail (5), (4) will have to amount to something stronger like:

(4*) From a God's eye-view, or all things considered, contextualism and invariantism provide equally sufficient and independent explanations of the behavioral effects of vague expressions.

The idea of $\left(4^{*}\right)$ is that given all the facts, the choice between contextualism and invariantism is underdetermined. However, although it might entail (5), (4*) is possible only if the following is false:

(EE) The Principle of Explanatory Exclusion: there can be only one complete and independent explanation of any one event.

Jaegwon Kim defends this principle, which reflects or embodies both explanatory and causal realism. ${ }^{9}$ According to the explanatory realist, having an explanation is a form of knowing, which implies truth, which implies that there is an objective counterpart - the thing known - that is not itself a part of that piece of knowledge. ${ }^{10}$ In addition, the causal realist claims that

\footnotetext{
9 'Explanatory Realism, Causal Realism, and Explanatory Exclusion', Midwest Studies In Philosophy 12(1), (1988), pp. 225-39, at p. 233.

10 Kim, p. 225.
} 
'every event has a unique and determinate causal history whose character is entirely independent of our representation of it. ${ }^{11}$ At any rate, it is not my aim here to defend EE, although it seems plausible. The important point is that if EE were correct, (4) would not even suggest $\left(4^{*}\right)$, since EE entails that $\left(4^{*}\right)$ is impossible.

Thus, for (4) to be more than a weak epistemic claim it must be construed as $\left(4^{*}\right)$, but $\left(4^{*}\right)$ is at odds with a realist view of causal explanation. Unger seems to intend this, however, instead opting for an instrumentalist view of explanation (at least when it comes to semantic theories). Consider the following passage:

In discussions of language, few things may be taken as even relatively basic: On the one hand, there are certain people (or other 'users') making marks or sounds. On the other hand, there are certain effects achieved on people as regards their conscious thought, their experiences, and, most important, their behavior. Everything linguistic, in between, is an explanatory posit.

Where such posits are made, observable phenomena - and even all objective (concrete) facts - get left behind. Then, we might expect a certain latitude, or room for descriptive maneuver, where alternative formulations may have equal claims to propriety. This suggests the idea that, for a given group of speakers, there is no single semantics of that group. Rather, we may formulate various explanations of the people's production of effects on each other, each formulation assigning a different semantics for the population. Different total explanations of behavior each allow for a different semantic approach. ${ }^{12}$

These comments suggest that Unger is less than a realist, and is probably an instrumentalist, when it comes to interpretations cum explanations. According to the instrumentalist view, being the 'correct' explanation means being the most 'useful' explanation, and being useful is independent of denoting something objectively real. Thus, if interpretations are types of explanations, then 'correct' interpretations are just pragmatic posits without ontological purchase. Privileging one interpretation over another would be a matter of utility and not veracity. If two interpretations were equally useful, there would be no fact of the matter as to which is correct, and any choice between them would be arbitrary.

11 Kim, p. 230.

12 Philosophical Relativity, p. 6. 
Thus, $\left(4^{*}\right)$ and its attending instrumentalism would entail (5). But why accept the ensemble? Unger's case for PR requires the inference from (4) to (5), which seems to require something like $\left(4^{*}\right)$, which in turn requires a denial of EE. Again, however, Unger's assuming a certain view on explanation is arguably tantamount to assuming that there is an answer (an anti-realist one) to a philosophical question about explanation. And, as I will later argue, this threatens to render his overall case for PR self-defeating.

We will now consider (2) in light of a worry about (4). Recall that (2) allows $\left(4^{*}\right)$ to be stated as: All things considered, we cannot determine what vague expressions mean. It is important to note that Unger is talking about the meaning of expressions, viz. utterances and sentence tokens. And, in this vein one might think that it is trivially true that the meaning of an expression is relative. John Searle, for example, has forcefully argued that semantics is not intrinsic to syntax. ${ }^{13}$ That is, meaning is not intrinsic to expressions qua sentence tokens. Rather, expressions have a derived or imputed meaning relative to the intentions of the speaker. Speakers/writers use expressions to convey meaning, but expressions qua sounds/symbols have no intrinsic meaning. But if Searle is correct, what would it mean to say that all things considered we cannot determine what a particular expression means? If Searle is correct then an expression has meaning only in so far as somebody is using or interpreting it as conveying or having a certain meaning. In this case, why could we not simply ask the speaker what she meant by the vague expression, whether, say, she meant 'flat' in the absolute or relative sense? Indeed, one might take the extensive literature disputing contextualism and invariantism to be evidence of the discovery that philosophers have often meant different things by the term 'know.'

Thus, $\left(4^{*}\right)$ seems plausible (if at all) only if we reject something like Searle's view on meaning. That is, only if something like (2) is correct. And indeed, (2) represents what appears to be Unger's commitment to a behaviorist view on semantics, one which construes the meaning of an expression in terms of its publicly observable effects and not in terms of any alleged content the speaker intended to convey. That is, (2)'s claim that there are no 'objective facts' that determine which interpretation is correct seems to be Unger's way of saying that there are no publicly observable facts

13 The Rediscovery of the Mind (Cambridge, MA: MIT Press, 1992), in Ch. 9. 
that determine the correct interpretation. That Unger means this is suggested by the following statement:

... we take the same attitude toward the relevant psychological states and processes as we take toward language: They are correctly attributed only to the extent that they serve to explain, however directly or obliquely, purposive behavior, actual and potential. ${ }^{14}$

Thus, if two different interpretations of an expression are equally sufficient to explain the public effects, then those effects underdetermine the choice between them. Hence, those effects do not enable us to determine which meaning is correct. It seems that in this way (2) can be supported by a behaviorist view of meaning, and it is hard to see an alternative support. But it is also hard to see why we should accept this view on meaning. If one accepts Searle's point about meaning, we have to consider the speaker's intentions in order to determine the meaning of an expression. At any rate, Unger seems to assume that we must accept his view on meaning, rather than a view like Searle's. Furthermore, assuming a behaviorist view amounts to assuming that there is an answer (a behaviorist one) to a philosophical question about meaning. Thus, once again, one of Unger's premises threatens to render his overall case for PR self-defeating.

My worries about (2) correspond to my worry about the inference from (8) to (9). Indeed, the argument is invalid at this point, since (8) does not follow from (9). Sometimes Unger speaks about vague expressions, and at other times he talks simply about 'the problems,' with the understanding that the problems in view are the ones that are vaguely expressed. His PR thesis typically lacks the 'expression' qualification, but his discussion and arguments almost invariably employ it. Thus, Unger is either equating 'expressions of certain philosophical problems' with 'certain philosophical problems,' or he is inferring a fact about the latter from a fact about the former. In my formulation I opted for the latter construal, since PR would be uninteresting (because trivially true) if it were merely the claim that expressions of certain philosophical problems were susceptible to rival interpretations and thus rival answers. Accordingly, we need to ask what validates the inference from (8) to (9).

14 Philosophical Relativity, p. 8. 
Again, the answer seems to be a behavioristic view of meaning, according to which utterances are the ultimate bearers of meaning, or, meaning exists only as a publicly observable entity or effect. That is, we can attribute meaning only in so far as we can do so on the basis of publicly observable facts/effects. ${ }^{15}$ This implies that the meanings of my thoughts are determined by behavioral facts. Thus, we cannot determine the meaning of a vague expression by appealing to alleged non-behavioral mental facts, such as the speaker's intended meaning.

Such a view on semantics would seem to validate the inference from (8) to (9). However, this view is both implausible and contentious. The view presupposes an answer to a philosophical question about the ultimate bearers of meaning. Once again, this threatens to render his overall case for PR self-defeating.

Finally, (2) is a critical plank in the case for PR. Without it, there is nothing to stop us from proceeding inferentially from (8) to:

(9*) There are multiple ways of interpreting vaguely expressed philosophical problems.

And so

$(10 *)$ There may be a distinct answer for each way of interpreting a vaguely expressed philosophical problem.

But $\left(10^{*}\right)$ is consistent with PO. Furthermore, for those not willing to grant (2), the foregoing two premises express a plausible account of the ambiguities often found in philosophical disputes. Namely, if an expression of a philosophical problem is vague, then there are probably as many definite answers to 'the' problem as interpretations of its expression.

It is time to consider whether and how Unger's defense and/or assertion of PR might be self-defeating. ${ }^{16}$ I would like to conclude this paper by arguing that PR can avoid double self-defeat only by

15 As I earlier noted, Unger ties behavior and thought together in that a thought is correctly attributed to a person only in so far as that thought can 'serve to explain, however directly or obliquely, purposive behavior, actual and potential' (Philosophical Relativity, p. 8).

${ }_{16}$ The specific challenge here raised for PR has its ancestry in the long-standing worry that various forms of relativism are self-defeating; this sort of concern is famously displayed in Plato's Theaetetus, where Socrates argues that Protagorean Relativism is self-defeating. 
an ad hoc limitation of its scope. By 'double self-defeat' I refer to both of the following two ways PR can suffer self-defeat. The first type I will call assertive self-defeat: For any assertion A, A is assertively self-defeating if A entails not-A. Since PR says that certain philosophical problems lack definite answers, PR will suffer assertive self-defeat if PR is itself a definite answer to one of those problems.

The second type I will call argumentative self-defeat: For any argument $\mathrm{A}$ with premises $\mathrm{P}_{1}, \ldots, \mathrm{P}_{\mathrm{n}}$, and conclusion $\mathrm{C}$ : $\mathrm{A}$ is self defeating if for some P, C entails not-P. Since PR says that certain philosophical problems lack definite answers, PR will suffer argumentative self-defeat if a premise in the argument for PR is itself an answer to one of those problems. In the foregoing, I noted several premises that seem to fit this description (there may be others, of course) $:{ }^{17}$

- Premise (2) answers to What are the ultimate bearers of meaning?

- Premise $\left(4^{*}\right)$ answers to Can there by only one complete and independent explanation of a single event?

- Premise (5.1) answers to How many distinct semantic theories are possible, and what accounts do they give?

For convenience, I will call premises (2), (4*), and (5.1) the 'threat set.'

The critical question is whether PR or any member of the threat set answers a question among those that PR says are without an answer. According to PR, the incriminated questions are those whose expressions are vague. Unfortunately, Unger does not give us much to go on for determining whether PR or any member of the threat set answers to a vague question. He does offer examples of terms that usually render vague those expressions that employ them. Among those he mentions are 'know,' 'certain,' 'cause,' 'explain,' 'can,' and 'free.'18 The list is not comprehensive; he says there are others. Nevertheless, given his list of examples, it seems likely that the questions answered by the threat set will be incriminated.

17 I previously noted that the motive for PR - its alleged explanandum - is itself a claim presuming an answer to something like 'What does philosophical progress amount to, and how could we know if it occurs?' However, since the motive is not a premise in the case for PR, it amounts to a potential inconsistency among Unger's statements, but not a potential source of self-defeat.

18 Philosophical Relativity, p. 6. 
Thus, it seems that Unger faces a choice between three options:

(a) PR answers to a vague question.

(b) Some member of the threat set answers a vague question.

(c) Neither (a) nor (b).

On either (a) or (b), PR suffers from self-defeat. If both (a) and (b), PR suffers from double self-defeat. If (c), then the extension of 'vague questions' must be appropriately limited in scope. However, narrowing the scope of PR in this way would seem entirely ad hoc, especially considering that PR and the members of the threat set answer potentially vague philosophical questions. Thus, it seems that PR and the case for PR can avoid forms of self-defeat only by an ad hoc limitation of PR's scope.

Texas AE'M University

College Station, TX, USA robertkgarcia@gmail.com 